\title{
Brief on Catalytic Reactions to Maximize Production and Minimize Pollution (MPMP)
}

\author{
SSEH Elnashaie* \\ Department of Chemical and Biological Engineering, Canada
}

*Corresponding author: SSEH Elnashaie, Department of Chemical and Biological Engineering, Vancouver, Canada

Submission: 㙁 October 26, 2017; Published: 海 November 10, 2017

\section{Opinion}

One of the main techniques for pollution control and achieving green technology is to achieve MPMP. Almost all catalytic reactions in the Petroleum refining and petrochemical industry are reversible and therefore their conversion is limited by the thermodynamic equilibrium. This conservative limitation can be broken by using selective membranes to remove one of the products. In this couple of pages editorial this revolutionary concept leading to MPMP is used for the dehydrogenation reaction where the selective membranes are used for the perm-selective removal of hydrogen [1-3]. These membranes have $100 \%$ selectivity for the removal of hydrogen. Most efficient configuration is when in the other side of the membrane is a hydrogenation reaction and the flows in the two sides of the membrane are counter-current. Such MPMP for catalytic reactors is essential part of Sustainable Development Engineering (SDE) which is an important subsystem of Sustainable Development (SD). The removal of one, or more, of the products relaxes this limitation and increases the conversion of the reaction; this relaxation increases as the removal of the product(s) is increased. The optimal utilization of this approach leads to MPMP approaching green technology and is a part of SDE. This editorial is concentrating on the removal of hydrogen from a dehydrogenation reaction, mainly ethyl-benzene to styrene [1-3], using hydrogen perm-selective membranes. The rate of hydrogen removal from the reaction side depends upon the type of the membrane and also the hydrogen driving force between the two sides of the membranes. This driving force increases when there is a hydrogenation reaction in the other side of the membrane. In this editorial a hydrogenation reaction of nitrobenzene to aniline is taking place on the other side of the membranes.

Figure 1 shows a schematic diagram for this novel integrated membrane reactor. Figure 2 shows the hydrogen profiles for both co-current and counter-current configurations. For counter-current case, feed is from the right for the hydrogenation compartment; otherwise all feeds are from the left. The counter-current is obviously more efficient.

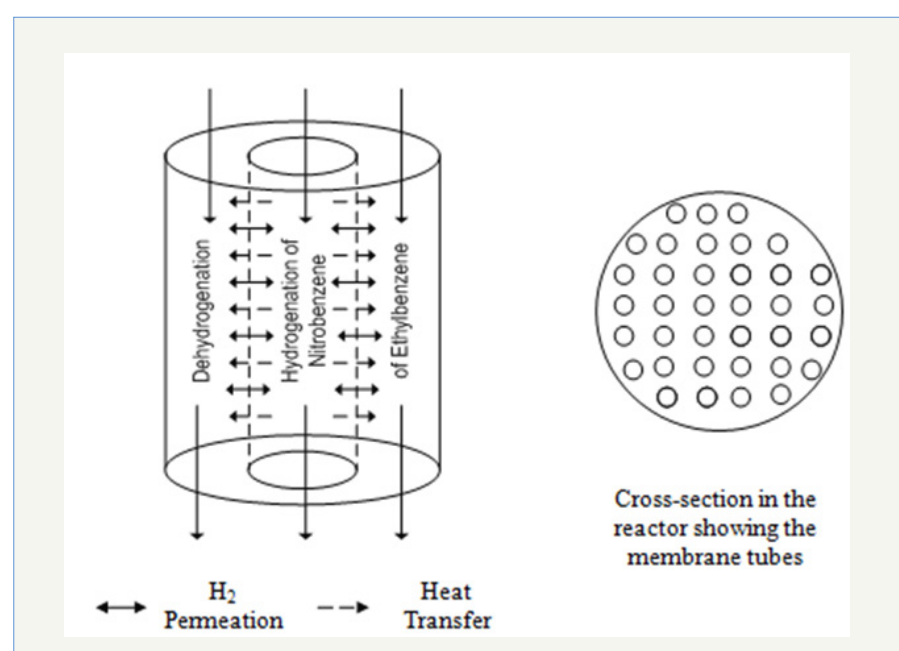

Figure 1: Schematic diagram showing integrated reactor configuration.

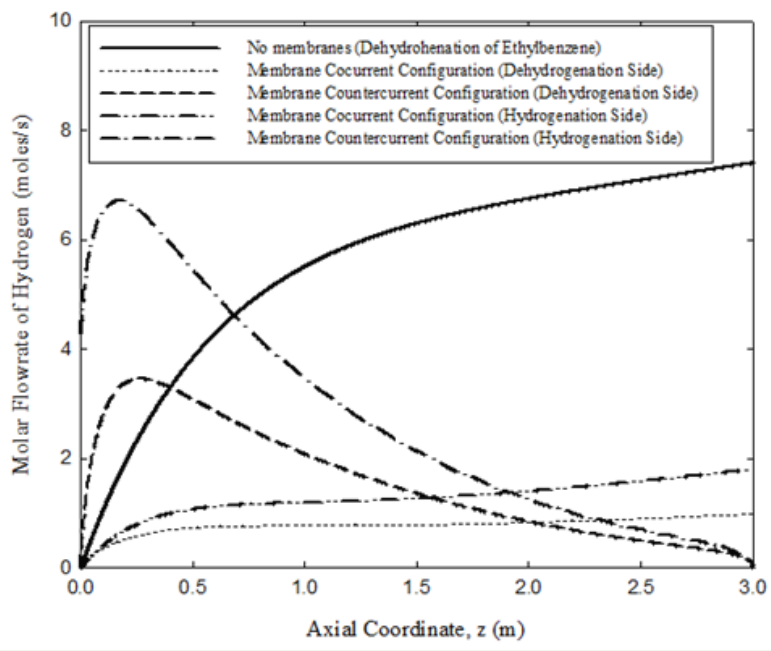

Figure 2: Hydrogen profiles for different configurations/ sides. 


\section{References}

1. She Y, Han J, Ma YH (2001) Palladium membrane reactor for the dehydrogenation of ethylbenzene to styrene. Catal Today 67: 43-53.

2. Hermann Ch, Quicker P, Dittmeyer R (1997) Mathematical simulation of catalytic dehydrogenation of ethylbenzene to styrene in a composite palladium membrane reactor. J Membr Sci 136: 161-172.

3. Abashar MEE (2003) Coupling of ethylbenzene dehydrogenation and benzene hydrogenation reactions in fixed bed catalytic reactors. Chem Eng Pro 43(10): 1195-1202. 